\title{
Piyoderma Gangrenozum: 20 Olgunun Retrospektif Değerlendirilmesi
}

\section{Pyoderma Gangrenosum: Retrospective Evaluation of 20 Cases}

\author{
Zehra Aşiran Serdar, Şirin Yaşar, Pembegül Güneş* \\ Haydarpaşa Numune Eğitim ve Araştırma Hastanesi, Deri ve Zührevi Hastalıklar Bölümü, İstanbul, Türkiye \\ *Haydarpaşa Numune Eğitim ve Araştırma Hastanesi, Patoloji Bölümü, İstanbul, Türkiye
}

\section{Özet}

Amaç: Bu çalışmanın amacı piyoderma gangrenozum (PG) tanısı alan hastalardaki klinik özelliklerin, eşlik eden sistemik hastalıkların ve tedavi protokollerinin incelenmesidir.

Gereç ve Yöntem: 2003-2009 yılları arasında kliniğimizde PG tanısı konulan 20 hasta çalışmaya alındı. Hastalar klinik özellikleri, eşlik eden sistemik hastalıkları ve tedavi protokolleri açısından retrospektif olarak incelendi.

Bulgular: 6 yıllık izlemde, 11'i kadın ve 9'u erkek, yaşları 19-75 arasında değişen ( yaş ortalaması 45ะ16,39), 20 PG'li hasta çalışmaya alındı. Lezyonlar 3 hastada (\%16) papül, 1 (\%5)'inde bül, 1 (\%5)'inde eritemli plak ve $15(\% 74)$ 'inde püstül şeklinde başlamıştı. On dört (\%70) hastada tek lezyon bulunurken diğer hastalarda çok sayıda lezyon bulunmaktaydı. Lezyonlar yerleşim yerine göre en sık 14 (\%70) hastada alt ekstremiteydi. Piyoderma ganrenozumlu hastalarda en sık eşlik eden hastalık inflamatuvar barsak hastalığıydı (kolitis ülseroza n: 4 ve Crohn hastalığı n: 2 toplam n: 6, \%30). Diğer eşlik eden hastalıklar arasında vitiligo (n: 1, \%5), Behçet hastalığı ( $n: 1, \% 5)$, hidradenitis süpürativa ( $n: 1, \% 5)$, derin ven trombozu ve pulmoner emboli $(n: 1, \% 5)$, pangastrit ( $n: 1, \% 5)$, akut böbrek yetmezliği ( $(n: 1, \% 5)$, sistemik lupus eritematozus ( $n: 2, \% 10)$ ve iatrojenik immünsüpresyon ( $n: 1, \% 5)$ bulunmaktaydı. Sistemik kortikosteroidler en sık uygulanan tedaviydi $(n=16, \% 80)$. Hastaların tamamında tedaviye yanıt tam olarak alındı.

Sonuç: Çalışmamızda piyoderma gangrenozuma sistemik hastalıklardan en sık inflamatuvar barsak hastalıkları eşlik etmekteydi. Olguların çoğunda lezyonlar alt ekstremitede, tek lezyon şeklindeydi ve tedavide en iyi yanıt sistemik kortikosteroidlerle sağlanmıştı. (Türkderm 2011; 45: 83-7)

Anahtar Kelimeler: Piyoderma gangrenozum, eşlik eden sistemik hastalıklar, tedavi

\section{Summary}

Background and Design: The objective of this study is to examine the clinical properties, comorbid systemic diseases and the treatment protocols of the patients diagnosed with pyoderma gangrenosum (PG).

Material and Method: Between 2003 and 2009 years, 20 patients diagnosed with pyoderma gangrenosum were evaluated in this study. The clinical properties, comorbid systemic diseases and the treatment protocols were examined retrospectively. Results: In a six-year period, 20 patients with PG (11 female and 9 male), ranging in age from 19 to 75 (mean age $45 \pm 16.39$ years) were evaluated. Lesions had started as papule in $3(16 \%)$ patients, as bullous in $1(5 \%)$ patient, as erythematous plaque in $1(5 \%)$ patient and as pustule in $15(74 \%)$ patients. Whereas $14(70 \%)$ patients had single lesion, the other patients had multiple lesions. The lesions were located at lower extremities in 14 (70\%) patients most frequently, The most frequent comorbid disease in patients with pyoderma gangrenosum was inflammatory bowel diseases (colitis ulcerosa $n: 4$ and Crohn disease $n: 2$ total n: 6, 30\%). The other comorbid diseases included vitiligo (n: 1, 5\%), Behcet's disease (n: 1,5\%), hidradenitis suppurativa (n: 1, 5\%), deep venous thrombosis and pulmonary embolism (n: 1, 5\%), pangastritis ( $n: 1,5 \%)$, acute renal failure (n: 1, 5\%), systemic lupus erythematosus (n: $2,10 \%)$ and iatrogenic immunosuppression ( $n: 1,5 \%)$. Systemic corticosteroid therapy was the most common treatment $(n=16,80 \%)$. The treatment response was $100 \%$ in all patients.

Conclusion: In our study, inflammatory bowel diseases were the most frequent comorbid diseases with pyoderma gangrenosum. Most of cases were as single lesions located in the lower extremities and the best treatment response was achieved by the administration of systemic corticosteroids. (Turkderm 2011; 45: 83-7)

Key Words: Pyoderma gangrenosum, associated with diseases, treatment 


\section{Giriş}

Piyoderma gangrenozum (PG)'un nedeni tam olarak bilinmemekle beraber, patogenezden anormal nötrofil kemotaksisinin patogenezden primer sorumlu olduğu düşünülmektedir. İlk kez Burnsting ve arkadaşları tarafından 1930 yılında inflamatuvar nötrofilik hastalıklar bir spektrum olarak tanımlanmışı ır ${ }^{1}$. Nötrofilik dermatozlar multisistemik bir grup hastalık olarak değerlendirilmektedir; başta PG, Sweet sendromu, subkorneal püstüler dermatoz, eritema elevatum diutinum ve Behçet hastalığı bu gruptaki en sık görülen hastalıklardı2,3. Bu dermatozlarda deri tutulumunun yanında inflamatuvar barsak hastalığı, romatoid artrit, hematolojik maliniteler ve monoklonal immünglobulin A (IgA) gammopatisi de hastalıklara eşlik etmektedir'. Çalışmamızda piyoderma gangrenozum tanısı alan hastalardaki klinik özelliklerin, eşlik eden sistemik hastalıkların ve tedavi protokollerinin incelenmesi amaçlandı.

\section{Gereç ve Yöntem}

Kliniğimizde Eylül 2003-Kasım 2009 yılları arasında piyoderma gangrenozum tanısı konulan 20 hasta çalışmaya alındı. Hastaların bilgisayar kayıtları retrospektif olarak incelendi. Hastalara telefonla ulaşıldı ve hastaneye çağrılarak tekrar muayeneleri yapıldı. Ayrıca dermatolojik bulguları, histopatolojik incelemeleri, tam kan sayımları, rutin biyokimya, yara kültürleri, eşlik eden hastalıkları ve tedavi protokolleri detaylı olarak gözden geçirildi. Veriler SPSS 11.0 programında değerlendirildi.

\section{Bulgular}

Yaş ortalaması 45 16,39 (19-75) olan, 11'i kadın ve 9'u erkek toplam 20 hasta çalışmaya alındı. Hastaların klinik özellikleri, eşlik eden sistemik hastalıkları ve tedavileri Tablo-1'de özetlenmiştir. Bir hastada (\%5) lezyon öncesi travma öyküsü mevcuttu. Lezyonlar 3 hastada (\%16) papül, $1(\% 5)^{\prime}$ 'inde bül, 1 (\%5)'inde eritemli plak ve 15 (\%74)'inde püstül şeklinde başlamıştı. Ancak daha sonra hastaların tamamında lezyonlar ülseratif karakter kazanmıştı. On dört (\%70) hastada tek lezyon bulunurken, 1 (\%5)'inde 3,3 (\%15)'ünde 4,1 (\%5)'inde 5 ve $1(\% 5)$ 'inde de 10 tane lezyon saptandı. Lezyonlar yerleşim yerine göre en sık 14 (\%70) hastada alt ekstremitede, $1(\% 5)^{\prime}$ inde penis şaftında, $2(\% 10)$ 'sinde inguinal bölgede, 2 (\% 10)'sinde el sırtında, 1 (\%5)'inde sol meme ve alt ekstremitede, 1 (\%5)'inde aksillar ve inguinal bölgede, 1 (\%5)'inde ise pubisteydi. Cinsiyete göre lezyonların dağılımı incelendiğinde kadınlarda en sık yerleşim $9(\% 81,7)$ hastada alt ekstremitede, $1(\% 9,1)^{\prime}$ inde aksillar ve inguinal bölgede, $1(\% 9,1)$ 'inde el sırtında, $1(\% 9,1)^{\prime}$ inde sol meme ve alt ekstremitedeydi. Erkeklerde ise en sık $5(\% 55,5)$ hastada alt ekstremitede, $1(\% 11,1)^{\prime}$ inde penis şaftında, $2(\% 22,2)$ 'sinde inguinal bölgede, $1(\% 11,1)^{\prime}$ inde el sırtında, $1(\% 5)^{\prime}$ inde ise pubisteydi.

\section{Tablo 1. Hastaların klinik özellikleri}

\begin{tabular}{|c|c|c|c|c|c|c|c|c|}
\hline Hasta & Cinsiyet & Yaş & Lezyon & Lezyon yeri & PG tipi & Patoloji & Eşlik eden hastalık & Tedavi \\
\hline 1 & K & 25 & Püstül & Bacak & Ülseratif & PG & Pangastrit & Kortikosteroid \\
\hline 2 & $E$ & 31 & Püstül & Penis şaftı & Ülseratif & PG & Akut böbrek yetmezliği & Kortikosteroid \\
\hline 3 & K & 36 & Püstül & Bacak & Ülseratif & PG & Crohn hastalığı & Kortikosteroid \\
\hline 4 & K & 37 & Papül & Bacak & Ülseratif & PG & SLE & Kortikosteroid \\
\hline 5 & $E$ & 65 & Büllöz & Bacak & Ülseratif & PG & Yok & Kortikosteroid \\
\hline 6 & $\mathrm{E}$ & 27 & Püstül & İnguinal & Ülseratif & PG & Yok & Kortikosteroid \\
\hline 7 & K & 38 & Eritemli plak & Bacak & Ülseratif & PG & Yok & Kortikosteroid \\
\hline 8 & $\mathrm{E}$ & 54 & Püstül & Bacak & Ülseratif & PG & $\begin{array}{l}\text { Derin ven trombozu } \\
\text { ve pulmoner emboli }\end{array}$ & Kortikosteroid \\
\hline 9 & K & 69 & Püstül & $\begin{array}{l}\text { 1. Sol meme } \\
\text { 2. Bacak }\end{array}$ & Ülseratif & PG & Yok & Kortikosteroid \\
\hline 10 & K & 75 & Püstül & Bacak & Ülseratif & PG & Yok & Kortikosteroid \\
\hline 11 & $E$ & 70 & Püstül & Bacak & Ülseratif & PG & Yok & Kortikosteroid \\
\hline 12 & K & 34 & Papül & Bacak & Ülseratif & PG & Kolitis ülseroza & Kortikosteroid \\
\hline 13 & K & 63 & Püstül & $\begin{array}{l}\text { 1.Aksilla-ingiunal } \\
\text { 2.Aksilla-inguinal }\end{array}$ & Ülseratif & PG & Hidradenitis süpürativa & $\begin{array}{l}\text { Kortikosteroid ve } \\
\text { siklosporin }\end{array}$ \\
\hline 14 & $E$ & 48 & Püstül & El & Ülseratif & PG & Kolitis ülseroza & Siklosporin \\
\hline 15 & K & 49 & Püstül & Uyluk & Ülseratif & PG & Crohn hastalığı, SLE & Siklosporin \\
\hline 16 & E & 48 & Papül & İngiunal & Granülomatöz & PG & Vitiligo & Kortikosteroid \\
\hline 17 & $E$ & 30 & Püstül & Bacak & Ülseratif & PG & Behçet hastalığı & Kortikosteroid \\
\hline 18 & K & 19 & Püstül & Uyluk & Ülseratif & PG & Kolitis ülseroza & Kortikosteroid \\
\hline 19 & K & 40 & Püstül & El & Ülseratif & PG & Kolitis ülseroza & Siklosporin \\
\hline 20 & $E$ & 42 & Püstül & Pubis, göğüs,bacak & Ülseratif & PG & Böbrek transplantasyon & Kortikosteroid \\
\hline
\end{tabular}


Piyoderma gangrenozumlu hastalarda en sık eşlik eden hastalık inflamatuvar barsak hastalığıydı (IBH) (kolitis ülseroza $\mathrm{n}: 4$ ve Crohn hastalığı $\mathrm{n}: 2$ toplam $n: 6, \% 30)$. Diğer eşlik eden hastalıklar arasında vitiligo (n:1, \%5), Behçet hastalığı (n:1, \%5), hidradenitis süpürativa (n:1, \%5), derin ven trombozu ve pulmoner emboli ( $n: 1, \% 5)$, pangastrit $(n: 1, \% 5)$, akut böbrek yetmezliği (n:1, \%5), sistemik lupus eritematozus (SLE) (n:2, \%10) ve transplantasyon+iyatrojenik immünsüpresyon (n:1, \%5) saptandı. Cinsiyete göre eşlik eden hastalıklar incelendiğinde kadınlarda $4(\% 36,4)$ 'ünde IBH, 1 (\%9.1)'inde pangastrit, $1(\% 9,1)^{\prime}$ inde SLE, $1(\% 9,1)^{\prime}$ inde hidradenitis süpürativa, $1(\% 9,1)$ 'inde $\mathrm{SLE}+\mathrm{iBH}$ bulundu. Erkeklerde ise $1(\% 11,1)^{\prime}$ inde İH, $1(\% 11,1)$ 'inde akut böbrek yetmezliği, $1(\% 11,1)$ 'inde pulmoner emboli+ derin ven trombozu, 1 (\%11,1)'inde vitiligo, 1 (\%11,1)'inde Behçet hastalığı ve $1(\% 11,1)$ 'inde böbrek transplantasyon+iyatrojenik immünsupresyon saptandı.

Olguların histopatolojik incelemesinde 7 (\%35) olguda lökositoklastik vaskülit, 2 (\% 10)'sinde lenfositik vaskülitin eşlik ettiği saptandı. Sistemik kortikosteroid en sık uygulanan tedaviydi ( $n=16, \% 80)$. Diğer bir sistemik tedavi ise siklosporindi $(n=3, \% 15)$. Prednizolon hastalığın şiddetine göre günde 60-130 mg arasında giderek azalan dozlarda 16 hastada kullanıldı ve tedavi süresi 8-16 hafta arasında değişmekteydi. Siklosporin günde 4-5 mg/kg arasında 3 hastaya, 8-12 hafta arasında verildi. Hidradenitis süpürativa zemininde PG gelişen bir hastaya (\%5) ise kombine tedavi olarak prednizolon günde $60 \mathrm{mg}$ ve siklosporin tedavisi $5 \mathrm{mg} / \mathrm{kg}, 12$ hafta boyunca giderek azalan dozlarda verildi.

Tedavi ile hastaların tamamında \%100'e yakın yanıt alındı. Ancak üç (\%15) hastada tedavi sonrasında nüks gözlendi. Meme yerleşimi olan hastanın bacağında, hidradenitis süpü-

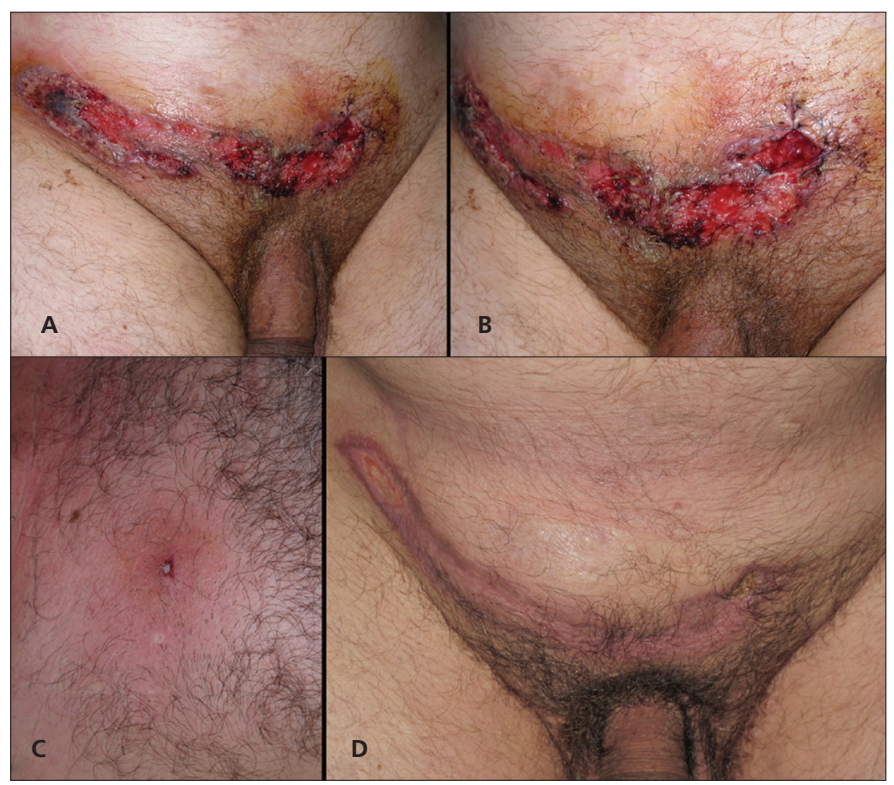

Şekil 1: a,b Genital bölgede yerleşmiş geniş çaplı ülseratif karakterde lezyon c Piyoderma gangrenozuma ait göğüs ön duvarında lezyon, d Sistemik steroid tedavisinden sonra lezyonda tam gerileme rativanın eşlik ettiği hastada aynı lokalizasyonda ve sağ bacak yerleşimli hastanın sol bacağında nüks izlendi. Böbrek transplantasyonu olan ve bu nedenle 5 yıldır immünsüpresif tedavi alan erkek hastada gelişen PG'nin tedavi öncesi ve sonrası (Şekil 1 a,b,c,d) ile eşlik eden herhangi bir hastalığı saptanmayan kadın hastanın inguinal bölgede yerleşmiş PG'nin tedavi öncesi fotoğrafları sırasıyla gösterilmiştir (Şekil 2 a,b).

\section{Tartışma}

Piyoderma gangrenozum nötrofilik hastalıklar spektrumunda yer alan, hızlı ilerleyen, ağrılı ve geniş ülserle karakterize nadir görülen inflamatuvar bir hastalıktır ${ }^{1,4}$. von den Driesch'in çalışmasında 20-50 yaş arası kadınların erkeklere göre bu hastalıktan daha fazla etkilendiği bildirilmektedir. Diğer reaktif nötrofilik dermatozlarda da kadın cinsiyet nedeni bilinmeyen şekilde daha sık etkilenmektedir ${ }^{5}$. Çalışmamızda yirmi olgunun 11'ini kadın hasta oluşturmaktaydı. PG infant, çocuk ve yaşlılarda daha nadir izlenmektedir. Buradaki olgu serisinde de çocuk ve infant bulunmazken 6 . dekat üzerinde 5 hasta saptandı (63-75 yaş). Piyoderma gangrenozumun sıklıkla minor travmalar sonucunda sıklıkla geliştiği ve köbner fenomenin olduğu söylenmekle beraber; olguların çoğunda travma öyküsü bulunmamaktadır ${ }^{6,7}$. Çalışmamızda 20 olgunun sadece birinde travma öyküsü saptandı. Piyoderma gangrenozumda tanı genellikle klinik özelliklerle konulur2,8. Lezyonlar ağrılı nodül, püstül ve / veya papül olarak aniden başlar ${ }^{4}$. Aktif lezyonu olan hastalarda eritemli halo ile çevrili, sınırları belirsiz, düzensiz, kırmızı-mor renkte, hemorajik, süpüratif ve nekrotik adeta" bataklık" manzarası görünümü klinik olarak PG'yi düşündürmelidir. Uluslararası bir PG sınıflandırması olmamasına rağmen, PG ülseratifpüstüler (klasik) form, büllöz, vejetatif, viseral, malin, peristomal, yüzeyel granülomatöz ve postoperatif olarak değerlendirilmektedir ${ }^{4}$. Olgularımızın çoğunda (\%74) lezyonlar püstül olarak başlamış, ancak daha sonra lezyonlar ülseratif karakter kazanmıştı ve hepsi klasik tipe uymaktaydı.

Piyoderma gangrenozumda lezyonlar yerleşim yeri olarak genellikle alt ekstremitede tibia ön yüzünde tek lezyon şeklindedir. Atipik formlar daha yüzeysel olup yüz, baş-boyun, meme kol, el üzerinde ve özellikle peristomal deride yerle-

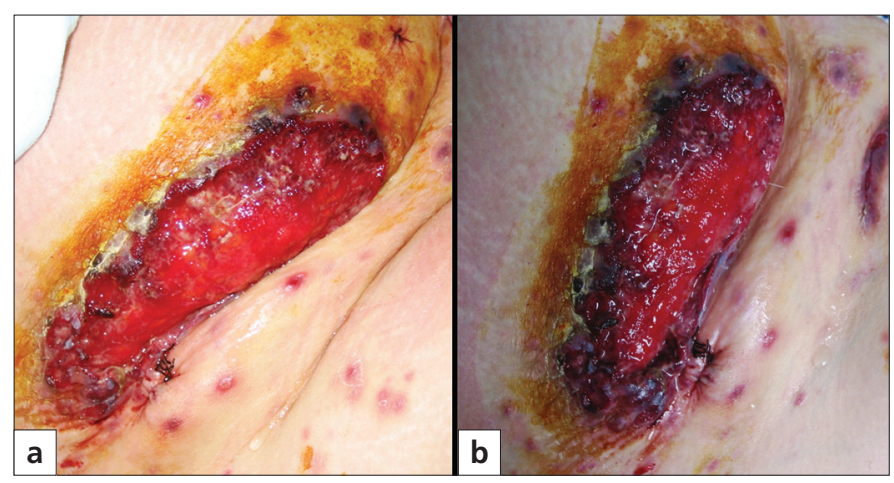

Şekil 2a, b: Sağ inguinal bölgede ülseratif piyoderma gangrenozuma ait görünüm ve etrafında çok sayıda uydu lezyon 
şim gösterebilirler ${ }^{1,5,9,10}$. Kim ${ }^{11}$, Güngör ${ }^{12}$ ve Farrell ${ }^{13}$ peniste atipik yerleşimli PG'li olgular bildirmişlerdir. Çalışmamızda da literatürle uyumlu olarak hastaların çoğunda PG tek lezyon ve alt ekstremite (\% 70) yerleşimliydi. Ayrıca bir hastada penis şaftında, 2'sinde inguinal bölgede, 2'sinde el sırtında, 1'inde sol memede, 1'inde aksillar ve inguinal bölgede ve 1 'inde de pubiste yerleşmişti. Mlika ve arkadaşlarının çalışmasında olgulardaki nüks oranını \%46 olarak bildirilmiştir ${ }^{1}$. Çalışmamızda ise 3 olguda (\%15) nüks saptandı.

Piyoderma gangrenosumda patogenez açık değildir, sapmış bir immünite suçlanmaktadır. Özellikle nötrofil kemotaksisinde ve fagositozda bozulma ilk planda olmakla birlikte nötrofilik infiltrasyonu başlatan faktör hala belirsizdir ${ }^{4}$. Histopatolojik özellikler spesik değildir ve PG aslında bir ekartasyon tanısıdır; patolojik özellikler lezyonun tipine ve süresine göre değişiklikler gösterir 2,8. Esas patoloji "nötrofilik infiltrasyon, abse formasyonu ve nekrotik alanlardır". Nötrofilik infiltrasyona bazen lökositoklastik vaskülit eşlik edebilir ${ }^{15}$. von den Driesch'in ${ }^{5}$ çalışmasında olguların \%73'ünde vaskülitin eşlik ettiği ve bunun \%68'inin lökositoklastik, \%32'sinin ise lenfositik olduğu bildirilmektedir. Buradaki olguların histopatolojik incelemesinde; 7 (\%35)'sinde lökositoklastik vaskülit, 2 (\%10)'sinde lenfositik vaskülitin eşlik ettiği saptandı.

Piyoderma gangrenozumlu hastaların \%50'sinden fazlasının sistemik hastalıklarla birliktelik gösterdiği bildirilmektedir ${ }^{5}$. En sık inflamatuvar barsak hastalıkları olmak üzere romatolojik ve hematolojik hastalıklara ${ }^{15}$, monoklonal gammopatilere', hidradenitis süpürativaya ${ }^{16}$ ve iyatrojenik immünsüpresyona ${ }^{17}$ veya malinitelere ${ }^{15}$ eşlik edebilmektedir. Çalışmamızda 20 hastanın 14 (\%70)'ünde sistemik hastalıklarla birliktelik saptandı. Hasselmann ve arkadaşları \%33 oranında inflamatuvar barsak hastalığıyla birliktelik olduğunu çalışmalarında bildirmişlerdir ${ }^{18}$. Literatürle uyumlu olarak olgularımızın \%30’unda inflamatuvar barsak hastalığı olduğu saptandı. Waldman ve arkadaşları PG gelişiminden 8 yıl sonra SLE tanısı alan bir olgu bildirmişlerdir ${ }^{19}$. İki olgumuzda da PG gelişimi sırasında yapılan tarama sonrasında SLE tanısı konuldu. SLE'de otoimmünite suçlanırken, PG'de otoimmüniteden çok humoral immünite, hücre aracılı immünite ve nötrofil fonksiyon bozukluğu ön plandadır, ancak son yıllarda T hücrelerinin rolü üzerinde durulmasına rağmen patogenez tam olarak açık değildir ${ }^{14}$. Hidradenitis süpürativa ile PG birlikteliği literatürde nadir olarak bildirilmektedir. Weng ve arkadaşlarının çalışmalarında hidradenitis süpürativa ile PG birlikteliği 6 olguluk seri ile bildirilmiştir ${ }^{16}$. Ancak bizim olgumuzdakine benzer şekilde 6 olgunun sadece birinde hidradenitis süpürativa zemininde PG geliştiği saptanmıştır. Hidradenitis süpürativada da fonksiyon bozukluğu gösteren nötrofiller ve immün yolak bozukluğu patogenezde yer almaktadır ${ }^{16}$. Rustin ve arkadaşları PG ve Behçet hastalığı birlikteliği olan bir olgu bildirmişlerdir ${ }^{20}$. Beş yıldır Behçet hastalığı nedeniyle takip ettiğimiz bir hastada PG gelişimi saptandı. Literatürde $P \mathrm{G}^{\prime}$ de akciğer tutulumunun nadir olduğu ve bu tutulumların nötrofilik infiltrasyonlar veya bazen de nodüler lezyonlar şeklinde görülebileceği olgu olarak bildirilmektedir ${ }^{1,2,21}$. Bir olgumuzda PG ile birlikte akciğer embolisi gelişmiştir ancak hastada derin ven trombozu olması nedeniyle pulmoner emboli buna bağlanmıştır. Haim ve arkadaşları böbrek transplantasyonlu ve pemfigus vulgarisli 2 olguda iyatrojenik immünsüpresyona bağlı PG gelişimi bildirmişlerdir ${ }^{17}$. Çalışmamızda bir olguda böbrek transplantasyonu nedeniyle 5 yıldır immünsüpresyon tedavi almakta iken PG gelişimi saptanmıştır.

Piyoderma gangrenozum tedavisinde ilk seçenek yüksek doz sistemik kortikosteroidlerdir. Hafif olgularda topikal ve intralezyonel kortikosteroidler kullanılabilir. Dirençli hastalarda immünsüpresif ilaçlar, intravenöz immünglobulin, biyolojik ajanlar yer almaktadır $4,8,15,22,23,24,25,26$. Literatürde genellikle prednison günde 40-120 mg olarak başlanabileceği bildirilmektedir. Siklosporinin günde 2-6 mg/kg olarak kullanılması önerilmektedir ${ }^{4,8,15}$. Reichrath ve arkadaşlarının çalışmasında prednisolon günde 0,3-1 $\mathrm{mg} / \mathrm{kg}$ ve siklosporin günde 5 $\mathrm{mg} / \mathrm{kg}$ birlikte ilk basamak tedavileri arasında yer almıştır ${ }^{15}$. Çalışmamızda prednizolon hastalığın şiddetine göre günde 60-130 mg arasında 16 hastaya ve siklosporin günde 4-5 $\mathrm{mg} / \mathrm{kg}$ arasında 3 hastaya kullanıldı. Hidradenitis süpürativa zemininde PG gelişen hastaya ise prednizolon günde $60 \mathrm{mg}$ ve $5 \mathrm{mg} / \mathrm{kg}$ siklosporin tedavisi birlikte verildi.

Cerrahi tedavi son derece tartışmalı olup, otörlerin çoğu PG'nin bir "paterji" reaksiyonu olduğunu ve travmanın lezyonları alevlendirebileceğini düşünmektedir. Bu yüzden PG'de cerrahi agresif yaklaşımlardan uzak durulmalıdır.

Sonuç olarak; çalışmamızda piyoderma gangrenozuma sistemik hastalıklardan en sık inflamatuvar barsak hastalıkları eşlik etmekteydi. Olguların çoğunda lezyonlar alt ekstremitede, tek lezyon şeklinde ve klasik tip PG ile uyumluydu. Tedavide en iyi yanıt sistemik kortikosteroidlerle sağlanmıştı. Piyoderma gangrenozum, tanısı zor ve patogenezi tam olarak açıklanamamıştır. Piyoderma gangrenozum romatolog, dermatolog, cerrahi ve iç hastalıkları uzmanlarını ilgilendiren disiplinlerarası bir konudur ve tanı-tedavi başarısı bu faktörlere bağımlıdır. Piyoderma gangrenozumda immün sistem ve özellikle nötrofil fonksiyon bozukluklarına yönelik yapılacak ayrıntılı çalışmalar bu antitenin daha iyi anlaşılmasını sağlayacak ve patogeneze ışık tutacaktır.

\section{Kaynaklar}

1. Mlika RB, Riahi I, Fenniche $S$ et al: Pyoderma gangrenosum: a report of 21 cases. Int J Dermatol 2002;41:65-8.

2. Brown TS, Marshall GS, Callen JP: Cavitating pulmonary infiltrate in an adolescent with pyoderma gangrenosum: A rarely recognized extracutaneous manifestation of a neutrophilic dermatosis. J Am Acad Dermatol 2000;43:108-12.

3. Vignon-Pennamen MD. The extracutaneous involvement in the neutrophilic dermatoses. Clin Dermatol 2000;18:339-47.

4. Ehling A, Karrer S, Klebl F, Schäffler A, Müller-Ladner U: Therapeutic management of pyoderma gangrenosum. Arthritis Rheum 2004;50:3076-84.

5. von den Driesch P: Pyoderma gangrenosum: a report of 44 cases with follow-up. Br J Dermatol 1997;137:1000-5.

6. Blitz NM, Rudikoff D: Pyoderma gangrenosum. Mt Sinai J Med 2001;68:287-97.

7. Crowson AN, Mihm MC Jr, Magro C: Pyoderma gangrenosum: a review. J Cutan Pathol 2003;30:97-107. 
8. Richetta AG, Maiani E, Carboni V et al: Pyoderma gangrenosum: case series. Clin Ter 2007;158:325-9.

9. Powell FC, Su WP, Perry HO: Pyoderma gangrenosum: classification and management. J Am Acad Dermatol 1996;34:395-409;410-2.

10. Ahmadi S, Powell FC: Pyoderma gangrenosum: uncommon presentations. Clin Dermatol 2005;23:612-20.

11. Kim TH, Oh SY, Myung SC: Pyoderma gangrenosum of the penis. J Korean Med Sci 2009;24:1200-2.

12. Güngör E, Karakayali G, Alli N, Artüz F, Lenk N: Penile pyoderma gangrenosum. J Eur Acad Dermatol Venereol 1999;12:59-62.

13. Farrell AM, Black MM, Bracka A, Bunker CB: Pyoderma gangrenosum of the penis. Br J Dermatol 1998;138:337-40.

14. Weedon D: The vasculopathic reaction pattern: Pyoderma gangrenosum. Weedon's skin pathology. 3.th Edition, China, Churchill livingstone elsevier, 2010;196-244.

15. Reichrath J, Bens G, Bonowitz A, Tilgen W: Treatment recommendations for pyoderma gangrenosum: an evidence-based review of the literature based on more than 350 patients. J Am Acad Dermatol 2005;53:273-83.

16. Ah-Weng A, Langtry JA, Velangi S, Evans CD, Douglas WS: Pyoderma gangrenosum associated with hidradenitis suppurativa. Clin Exp Dermatol 2005;30:669-71.

17. Haim S, Friedman-Birnbaum R: Pyoderma gangrenosum in immunosuppressed patients. Dermatologica 1976;153:44-8.
18. Hasselmann DO, Bens G, Tilgen W, Reichrath J: Pyoderma gangrenosum: clinical presentation and outcome in 18 cases and review of the literature. J Dtsch Dermatol Ges 2007;5:560-4.

19. Waldman MA, Callen JP: Pyoderma gangrenosum Preceding the Diagnosis of Systemic Lupus erythematosus. Dermatology 2005; 10:64-67.

20. Rustin MH, Gilkes JJ, Robinson TW: Pyoderma gangrenosum associated with Behçet's disease: treatment with thalidomide. J Am Acad Dermatol 1990;23:941-4.

21. Chahine B, Chenivesse C, Tillie-Leblond I et al: Pulmonary manifestations of Pyoderma gangrenosum. Presse Med 2007;36:1395-8.

22. Wollina U: Clinical management of pyoderma gangrenosum. Am J Clin Dermatol 2002;3:149-58.

23. Wollina U: Pyoderma gangrenosum-a review. Orphanet J Rare Dis 2007;2:19.

24. Trémezaygues L, Schmaltz R, Vogt T, Reichrath J: Management of pyoderma gangrenosum. An update on clinical features, diagnosis and therapy. Hautarzt 2010;61:345-53;354-5.

25. Miller J, Yentzer BA, Clark A, Jorizzo JL, Feldman SR: Pyoderma gangrenosum: a review and update on new therapies. J Am Acad Dermatol 2010;62:646-54.

26. Duarte AF, Nogueira A, Lisboa C, Azevedo F: Pyoderma gangrenosum-clinical, laboratory and therapeutic approaches. Review of 28 cases. Dermatol Online J 2009;15:3. 